\title{
Allograft Labral Reconstruction of the Hip: Expanding Evidence Supporting Greater Utilization in Hip Arthroscopy
}

\author{
Brian J. White $^{1,2} \cdot$ Shannon M. Constantinides ${ }^{3,4}$ (D) \\ Accepted: 10 December 2021 / Published online: 10 February 2022 \\ (C) The Author(s) 2022
}

\begin{abstract}
Purpose of Review The current review investigates outcomes and failure rates associated with arthroscopic circumferential allograft labral reconstruction of the hip, both as a revision and primary procedure in treating femoroacetabular hip impingement and labral-related pathology.

Recent Findings Numerous studies within the last decade have demonstrated excellent patient-reported outcomes, high rates of return-to-play in athletes, and low failure rates in patients having undergone arthroscopic circumferential allograft labral reconstruction of the hip. Removal of chronically diseased and injured labral tissue can eliminate a significant pain-generator from the hip joint. Additionally, circumferential reconstruction of the labrum restores the hoop fiber strength and fluid seal akin to what would be seen with native, healthy labral tissue. Recent research has shown that arthroscopic circumferential allograft labral reconstruction may be used not only in the revision setting, but as a primary procedure. Circumferential labral reconstruction should be considered when a surgeon feels that the labrum is irreparable or has failed previous repair.

Summary Arthroscopic circumferential allograft labral reconstruction of the hip can be utilized as treatment option not only in revision settings, but also in primary treatment for femoroacetabular impingement and labral pathology
\end{abstract}

Keywords Labral reconstruction of the hip · Allograft labral reconstruction

\section{Introduction}

While initially designed to resect damaged soft tissue, the goal of modern hip arthroscopy has shifted focus to preserving and restoring function within the hip joint and improving its biomechanics. Labral repair, which has been considered the standard treatment for hip impingement and labral tears, is becoming much more commonplace. However, considering a growing body of evidence demonstrating positive outcomes and low revision rates, we contend that labral reconstruction can be

This article is part of the Topical Collection on HIP/FAI

Shannon M. Constantinides rockharborresearch@gmail.com

1 Western Orthopaedics, Denver, CO, USA

2 Porter Adventist Hospital, Denver, CO, USA

3 Colorado Center of Orthopaedic Excellence, Colorado Springs, CO, USA

4 Rock Harbor Research Institute, 13 Corrine Place, Key Largo, FL, USA considered a primary treatment for femoroacetabular hip impingement (FAI) and labral tears, especially in such circumstances in which the labral tissue is deemed irreparable. A number of factors can contribute to poor healing with labral repair, thus, decreasing the labrum's ability to provide a functional fluid seal around the joint, and increasing the likelihood of continued pain, intra-articular injury, and joint dysfunction [1]. As such, labral reconstruction offers clear advantages including removal of unhealthy, painful labral tissue; complete access for reshaping the acetabulum and addressing pincer impingement; and incorporating a graft that will mimic the biomechanical benefits of a healthy, native labrum ${ }^{1}$. This article will provide a brief overview of our progress as a specialty, evidence to support current practices as they pertain to arthroscopic circumferential allograft labral reconstruction of the hip, and implications for future directions in hip preservation surgery.

\section{Historical Perspectives}

Due to an exponential surge in demand, the last two decades have seen unprecedented growth within the specialty of 
arthroscopic hip surgery. Used as a technique to treat intraarticular pathology, including FAI and labral tears, hip arthroscopy has become increasingly common. Data from 2006 to 2010 demonstrated a $600 \%$ increase in the number of arthroscopic hip surgeries being performed annually in the USA $[2,3]$, with a study by Bonazza and colleagues, which queried a large national data base, reporting that from 2008 to 2013 the number of arthroscopic hip procedures per patient increased by $378 \%$. Considering that labral reconstruction is somewhat still in its adolescence, more research is needed to calculate quantifiable trends in the occurrence of this procedure. However, the last few years have shown a noticeable increase in the numbers of studies focusing on labral reconstruction due to technological and evidence-based innovations in surgical techniques and largely promising and positive outcomes data [4-16]. Six meta-analysis or systematic reviews have been published in the last few years, alone, and point to equivalent or improved results with labral reconstruction compared to repair (Table 1) [7-9,11,17,18]. Likewise, at least 17 studies have been published within the last decade evaluating various outcomes of arthroscopic labral reconstruction using allograft $[4,5,9,10,12-14,16,19-27]$ and autograft [28-36] techniques (Table 2). Overall, current evidence has concluded that arthroscopic labral reconstruction of the hip is associated with improved pain and functional status, low rates of complications or need for revision surgery, and rare progression of arthritis.

\section{Labral Function}

Within the last decade, a number of cadaveric studies have demonstrated the importance of the acetabular labrum in preserving normal hip function [37-41]. Composed of a complex fibrocartilaginous matrix, the hip labrum in combination with the transverse acetabular ligament form an uninterrupted ring around the acetabulum[40]. During weight bearing and with hip range of motion, this tissue ring is exposed to forces exerting compression and elasticity in axial, load-bearing and circumferential directions [40]. The factors that allow the labrum and transverse ligament to endure such forces are what allow it to increase weightbearing surface area and evenly distribute contact pressure off the cartilage of the femoral head and acetabulum ${ }^{40}$. Furthermore, the labrum functions to preserve intra-articular fluid pressure within the femoroacetabular joint [40]. By creating a fluid seal, an intact labrum helps maintain the fluid pressurization required for stability of the hip against distraction forces and protection of the intra-articular cartilage matrix [37-40]. Labral tears as well as an insufficient labrum have been shown to be associated with loss of fluid pressurization within the joint [37-39]. Biomechanical research regarding these pathophysiological issues has demonstrated that labral reconstruction can restore the fluid seal, thus, restoring fluid pressurization and stability within the joint, and decreasing the damaging contact pressure and friction on the articular surfaces [37-39].

\section{Indications for Hip Labral Reconstruction}

While initially seen as a salvage procedure, our recommendation for primary labral reconstruction reflects the culmination of growing evidence supporting its benefit in revision settings and as a primary procedure to restore and preserve function when the labrum is deemed irreparable. This may include circumstances when labral tissue is compromised or otherwise inadequate or inappropriate for a repair, such as would be seen with congenitally or acquired labral deficiency, hypertrophic labra, ossified labra, or labral tissue that has been damaged,

Table 1 Systematic reviews/ meta-analyses on labral reconstruction 2019-2021

\begin{tabular}{|c|c|c|c|c|c|c|c|}
\hline & $N$ (studies) & $\begin{array}{l}N \\
\text { (hips/patients) }\end{array}$ & Graft & $\begin{array}{l}\text { M age } \\
\text { (years) }\end{array}$ & $\begin{array}{l}\text { M follow-up } \\
\text { (months) }\end{array}$ & Convert to THA & M improvement in mHHS \\
\hline Al Mana et al. $2019^{17}$ & 9 & 265 hips & $\begin{array}{l}\text { Allo (5) } \\
\text { Auto (4) }\end{array}$ & 35 & $37(12-61)$ & $5.70 \%$ & 28 (mHHS) \\
\hline Bessa et al. $2020^{18}$ & 7 & 402 patients & Auto & $44(16-72)$ & $66(12-120)$ & $0-13 \%$ & 28 (mHHS) \\
\hline Maldonado et al. $2020^{9}$ & 10 & 582 hips & Allo & $30(27-52)$ & $45(24-66)$ & & 39 (mHHS) \\
\hline Rahl et al. $2020^{7}$ & 8 & 537 hips & Auto & 37 & 29 & $\begin{array}{l}0-13.2 \% \text { (Auto) } \\
0-12.9 \% \text { (Allo) }\end{array}$ & 29 (mHHS) \\
\hline Safran et al. $2021^{11}$ & 7 & 228 hips & $\begin{array}{l}\text { Not } \\
\text { Reported }\end{array}$ & 38 & 35 & $3 \%$ & $\begin{array}{l}\text { PROs reported as improved } \\
\text { numeric data not reported }\end{array}$ \\
\hline Trivedi et al. $2019^{8}$ & 11 & 373 patients & $\begin{array}{l}\text { Allo (4) } \\
\text { Auto (6) } \\
\text { Mixed (1) }\end{array}$ & $36.6(28-43)$ & 12 & $0-23 \%$ & 24 (mHHS) \\
\hline
\end{tabular}

Auto autograft, Allo allograft, THA total hip arthroplasty, PRO patient-reported outcome, $m H H S$ modified Hip Harris score 


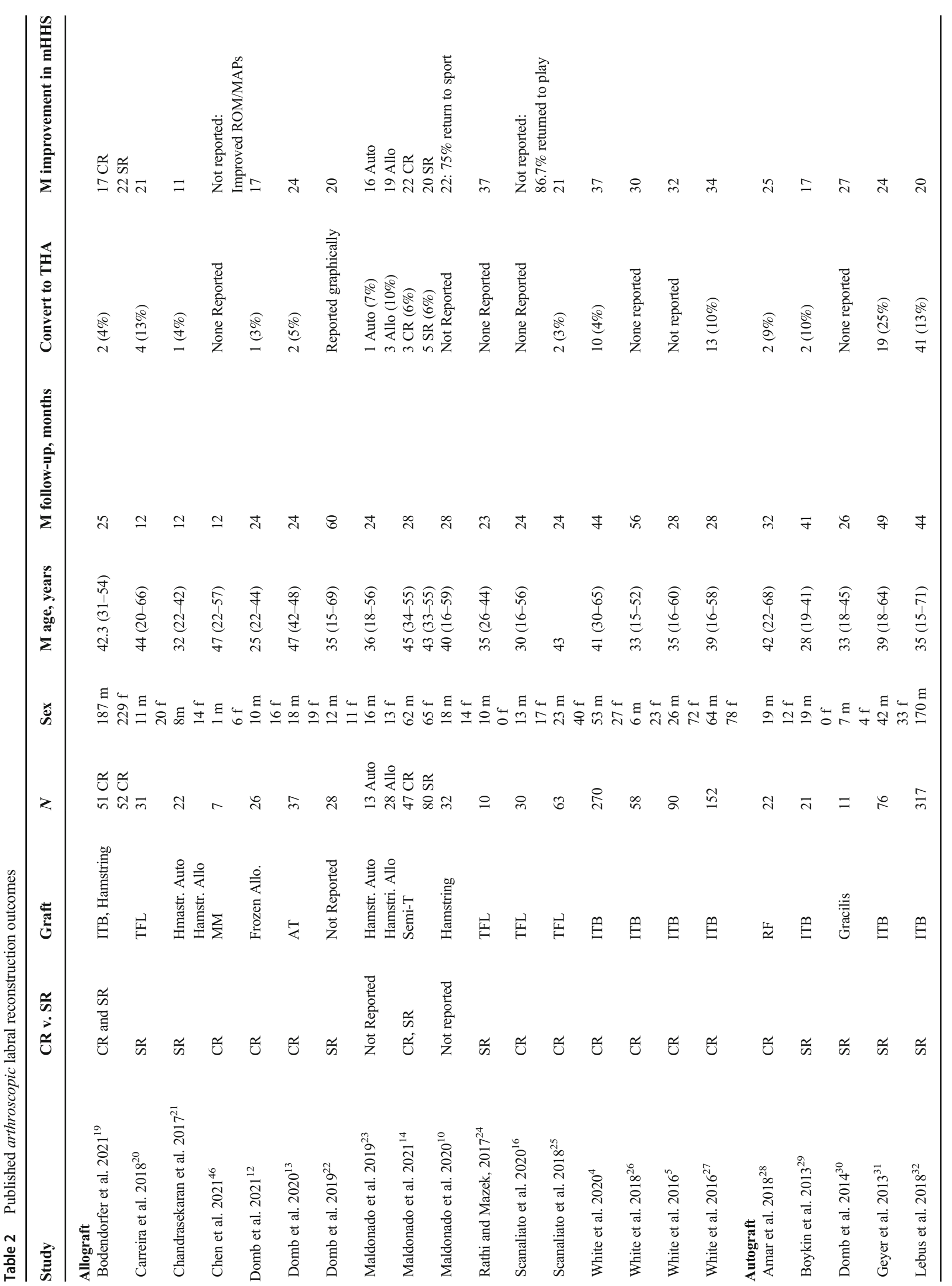




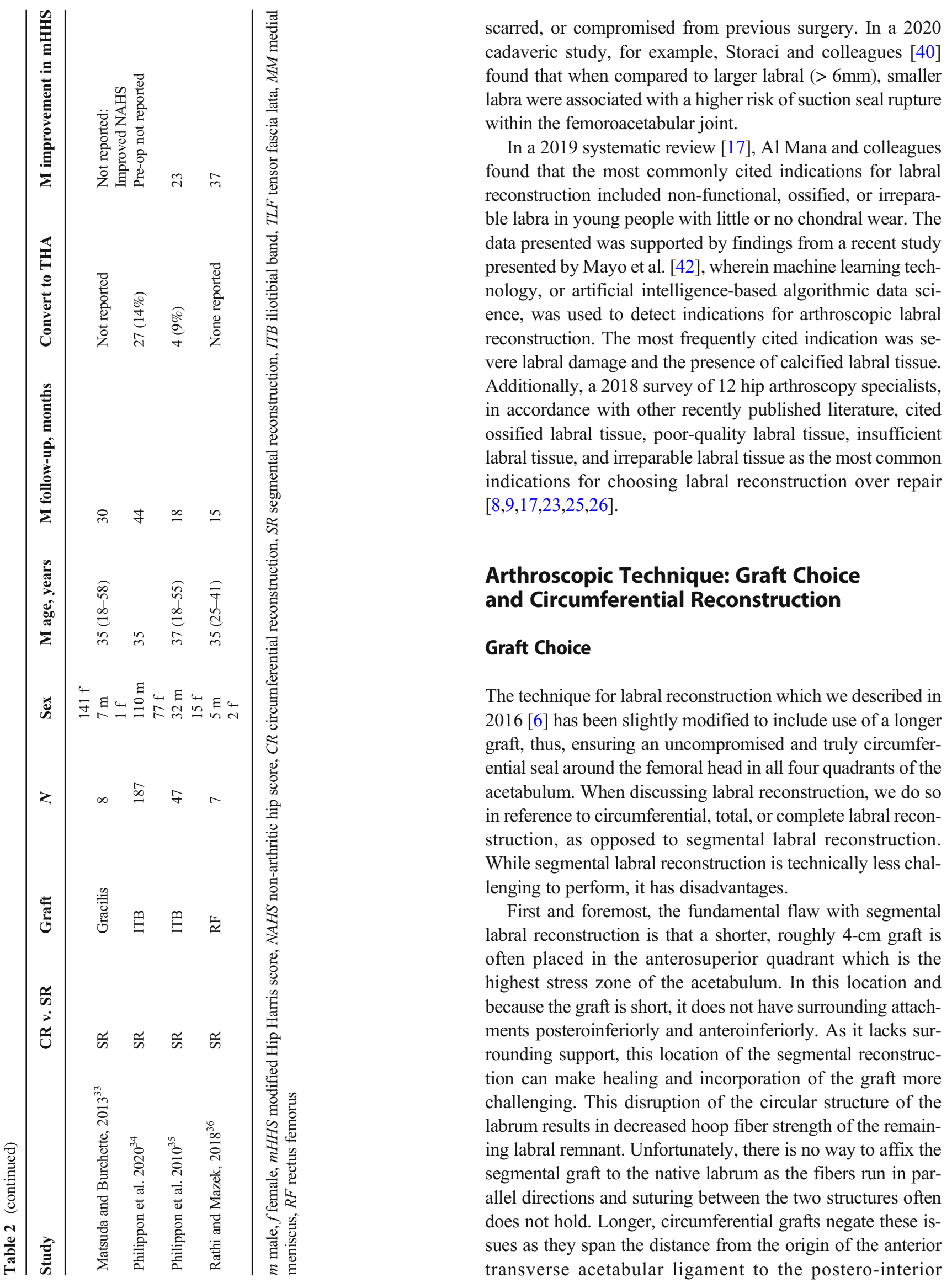


acetabulum and cover all four quadrants of the acetabulum. Much like a suspension bridge, circumferential grafts are stronger. They provide rigid fixation antero-inferiorly and posteroinferiorly to give greater support to the critical, highstress antero-superior acetabulum. In contrast, segmental grafts are placed in this zone of the acetabulum without surrounding support. The circumferential graft can reproduce the native fluid seal around the femoral head and thereby can more evenly distribute the forces associated with weight bearing and range of motion. Second, by removing only a segmental section of the labrum, the remaining, unhealthy, and highly innervated native posteroinferior and anteroinferior labral remnants remain in the joint and are vulnerable to further tearing and pain generation.

In addition to recommending circumferential labral reconstruction, we recommend the use of a frozen fascial allograft (AlloSource) [15]. Our preference was also substantiated by other surgeons in a recently published review, where $91.7 \%$ of high-volume hip arthroscopists reported a preference for use of allograft over autograft when performing labral reconstruc$\operatorname{tion}^{23}$. Likewise, in reviewing literature on labral reconstruction over the past decade, we found that the majority of study protocols, especially within the last few years, utilized allograft tissue (Table 2). Surgeon preferences for allograft included hamstring, fascia lata, anterior tibialis, and tissue bank acetabular labrum [23]. Other recent literature has documented use of the peroneus brevis [43-45] and medial meniscus [46] as alternate sources of allograft tissue. In a 2020 systematic review and meta-analysis, Rahl et al. [7] found that in regard to allograft choice, the most commonly utilized tissues included iliotibial band $(76.2 \%)$ and tensor fascia lata $(23.8 \%)$. It is important to note that several studies on labral reconstruction transitioned mid-study in protocol from autograft to allograft due to issues related to donor site morbidity. In a 2019 study investigating differences between auto and allograft in labral reconstruction, Maldonado and colleagues found slightly higher post-op modified Hip Harris scores (mHHS), and an improved mean mHHS (19 points) in their allograft group when compared to their autograft group [47]. In the conclusion of their study, Maldonado et al. stated that donor site morbidity in the autograft cohort may contribute to higher patient satisfaction in the allograft group. This was also consistent with our early experience, as donor site morbidity of the iliotibial band harvest site became the main driver in the direction of pursuing allograft.

\section{Circumferential Reconstruction}

Perhaps the most critical aspect of the procedure involves the meticulous treatment of the boney morphology causing the femoroacetabular impingement (FAI). During this stage of the operation, the femoral head neck junction (cam morphology) is reshaped to an anatomic, natural shape that will fit properly into the acetabulum. This eliminates impingement of the femoral head neck junction against the labral graft and improves both flexion and rotation of the hip. The acetabulum is circumferentially excoriated to prepare for biologic incorporation of the labral graft and pincer morphology, or over coverage, is removed when appropriate (Figures 1 and 2). If a pincer lesion is truly absent or in the case of acetabular dysplasia, the acetabular rim must be carefully prepared with a burr to create a bleeding response that will perpetuate osseous integration of the graft into the acetabular rim. It is critically important in this type of hip that great care be taken to excoriate the edge of the acetabulum without reducing the acetabular volume. In general, we recommend that $1 \mathrm{~mm}$ or less of bone be resected in the presence of a normal or low volume acetabulum to prepare for biologic incorporation of the labral graft. The cartilage on the acetabular edge is also stabilized and beveled to protect it from further injury and delamination. Following the conclusion of the bony work and preparation, torn or degenerative labral tissue is removed from its origin at the transverse acetabular ligament to the posteroinferior acetabulum. For purposes of orientation, the area from which labral tissue is resected spans an anteroinferior position (7:30 left hips and 4:30 right hips) to a posteroinferior position (4:00 left hips and 8:30 right hips).

With both sides of the joint reshaped and prepared, suture anchors are placed measuring 10 to $12 \mathrm{~mm}$ apart around the entire acetabular rim (Q-Fix, Smith \& Nephew). Anchors are placed from one of two direct anterolateral (DALA) portals, which allow access to both the anterior and posterior acetabulum. To avoid eversion of the labral graft, suture anchors should be placed as close to the cartilage border as possible. It is helpful to place all suture anchors before the acetabular graft is introduced into the joint to allow for optimal

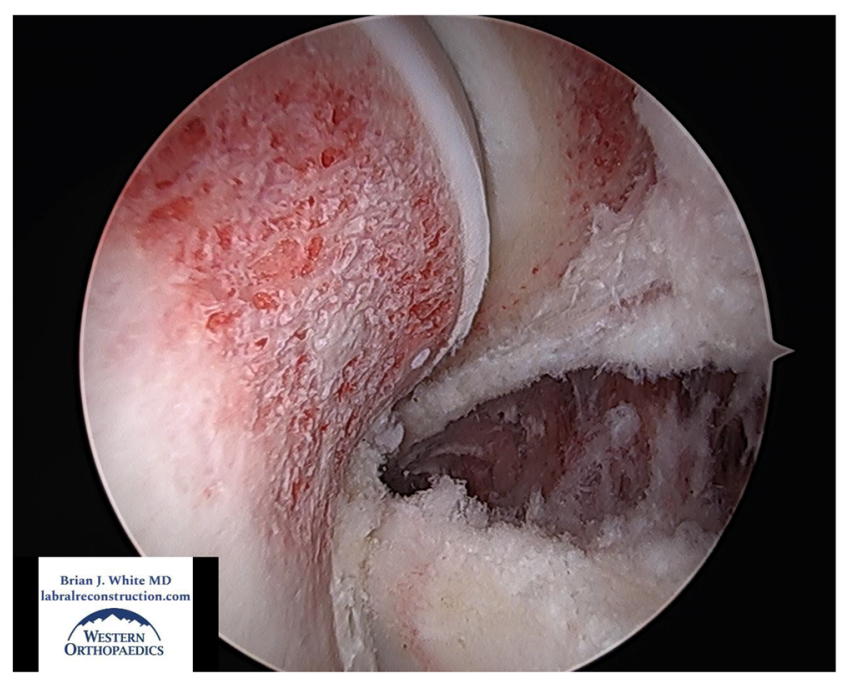

Fig. 1 View from the anteromedial portal in a left hip of a proper, complete femoral osteoplasty with an anatomic shape and an alpha angle in the mid $40 \mathrm{~s}$. Also seen is the pincer resection as the joint is reduced 


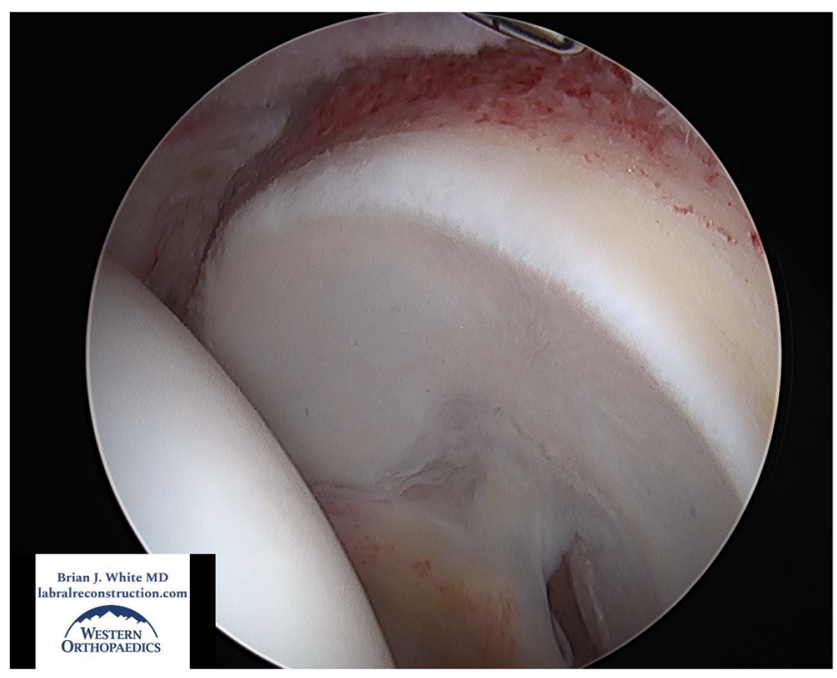

Fig. 2 View from the anterolateral portal in a left hip of a well-prepared acetabular rim. The pincer was resected, and the center edge angle was improved from 42 degrees to 34 . The cartilage was also well stabilized

visualization and anchor positioning. After all suture anchors have been placed, and before the graft is introduced into the joint, two small drill holes measuring approximately $0.6 \mathrm{~mm}$ in diameter are placed between each anchor site. The drill holes create vascular channels which foster osseous integration of the graft into the acetabular rim and are particularly helpful in areas where only the acetabular edge could be excoriated to avoid loss of cup volume (Figure 3 ).

Graft length is determined by measuring the length of the labral defect from front-to-back with a 4-mm-wide elevator. Approximately 3 to $4 \mathrm{~cm}$ are then added to the measurement to account for the nonlinear contour of the acetabular rim. After graft length has been calculated, the graft is meticulously prepared by tubularizing the fascial tissue. This is accomplished by folding the fascia into thirds or quarters and then passing a 2-0

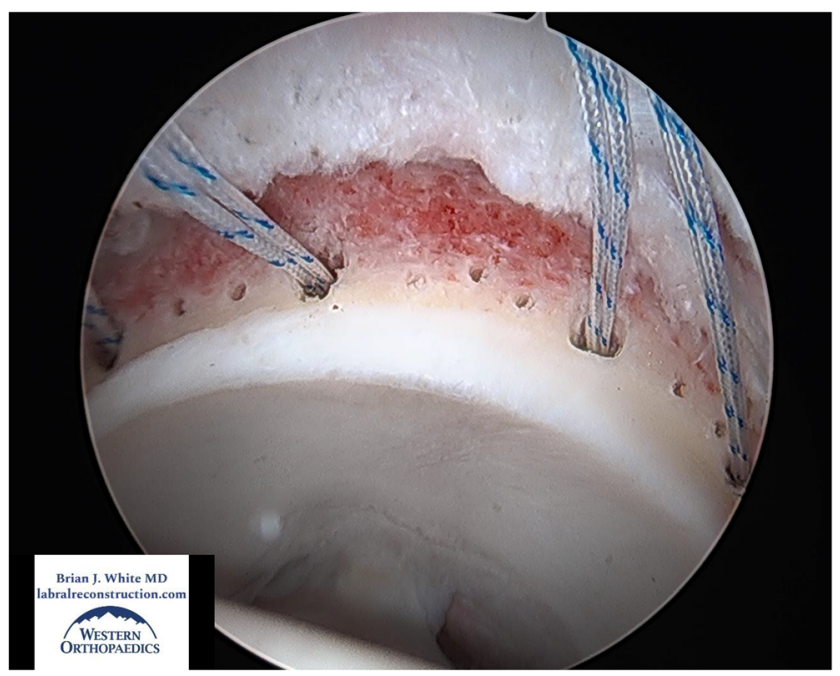

Fig. 3 View from the anteromedial portal in a left hip of "vascular channels" $0.6 \mathrm{~mm}$ in diameter between anchors to encourage healing and incorporation of the graft
Vicryl suture through several small bites in an accordion-like manner at the end of the graft. These are tied, and the suture tails are then attached to a graft master to maintain adequate tension on the graft. Using a 2-0 Vicryl suture, a baseball stitch is run from front to back through the graft, using intermittent circumferential wraps, to compress the tissue.

The preferred diameter of the final graft varies among surgeons. A larger diameter graft is easier to achieve a seal with the femoral head but takes up space during the operation and is harder to compress and achieve incorporation. In contrast, a smaller diameter graft is easier to compress and incorporate, but it is harder to obtain a final seal between the graft and the femoral head. Over the years, we have found that a final graft measuring 5 to $5.5 \mathrm{~mm}$ in diameter provides adequate material to establish a seal with the femoral head and can be rigidly fixed and compressed. This size also appears aesthetically proportionally appropriate.

Using a cannula, the graft is brought into the joint via the anterior DALA portal. A suture limb from the most anteroinferior anchor is tied directly to the graft in figure of eight fashion. With the graft fixed to the suture, the anchor is used as a pulley to advance the graft into the joint. Once in the joint, the graft is placed in provisional position around the acetabular rim with a probe. Once positioned, a probe through the anteromedial (AM) portal allows the surgeon to maintain tension on the graft. Sutures are secured for the first two to three anchors. The most difficult area to create a seal between the graft and the femoral head is the antero-superior zone as it represents a challenging transition for the rigid graft from the vertical anterior wall of the acetabulum to the horizontal/lateral zone of the acetabulum. To offset the potential of not having a seal between the graft and the femoral head in this section, the suture anchors are passed, but not tied, at the anterior-superior, lateral, and posterior positions around the acetabulum. The graft is then fixed posteroinferiorly to tension the graft so that it can follow the curvature of the antero-superior acetabulum.

After all sutures have been passed, the graft is tensioned and cut posteroinferiorly. It is important to note that the graft is cut in the joint to ensure that its length is appropriate. This is the advantage of the Front-to-Back technique as graft length is tailored in situ to avoid a mismatch between the graft length and the length and contour of the acetabulum [6]. For longer grafts, an additional portal (posterior and proximal to the antero-lateral $[\mathrm{AL}]$ portal) may be required to cut the graft. Using a grasper inserted through the AL portal to hold tension on the graft, the graft is cut using a beaver blade. At present, the length of a reconstructed labral allograft measures between 11.5 and $14.5 \mathrm{~cm}$ in length (Figures 4 and 5).

At the most posteroinferior aspect of the acetabulum, two anchors are placed only a few millimeters apart. Using an Elite Pass (Smith \& Nephew), the sutures from the distal anchor are passed through the graft and are then tied, while the sutures from the adjacent anchor are tied circumferentially 


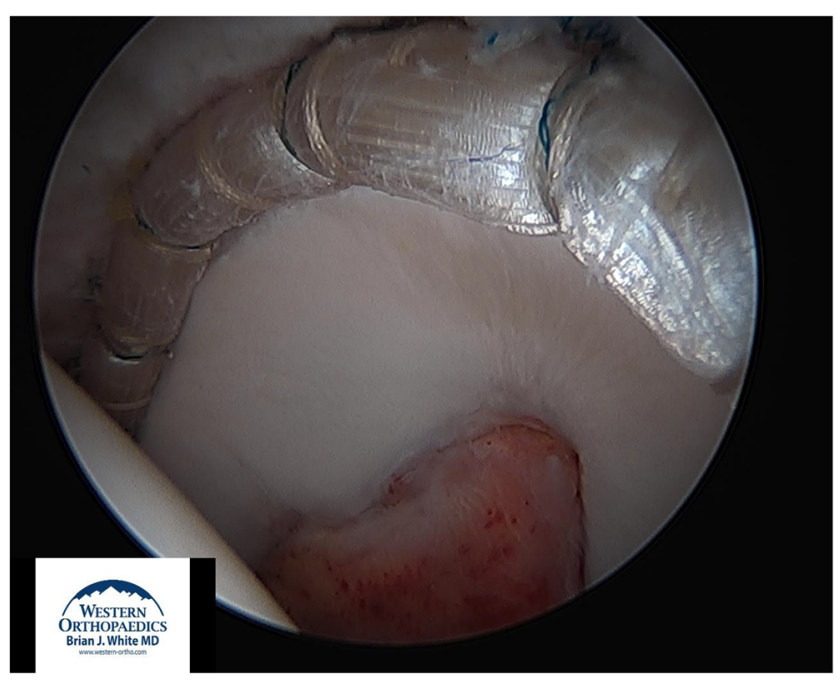

Fig. 4 View from the anterolateral portal of a left hip showing the anterior portion of a 13-cm allograft labral reconstruction fixed with 13 anchors

around the graft. With the graft now fixed antero-inferiorly and posteroinferiorly, the sutures in between can be secured. This is done in the peripheral compartment with the hip joint reduced or off traction. The camera is then moved to the $\mathrm{AL}$ portal and a cannula is positioned in the posterior DALA portal. The hip is then taken off traction which reduces the graft to the rim of the acetabulum and relieves tension on the anchors. Remaining sutures are tied in the peripheral compartment to ensure rigid fixation of the graft. It is absolutely critical that the graft form a perfect seal around the femoral head (Figure 6). Once the graft is rigidly fixed, dynamic testing under direct arthroscopic visualization is performed with the hip flexed and internally rotated. This is done to confirm that there is no graft impingement or joint instability. The hip capsule is closed using a \#1 Vicryl or permanent suture. The extent of capsular closure, which may include

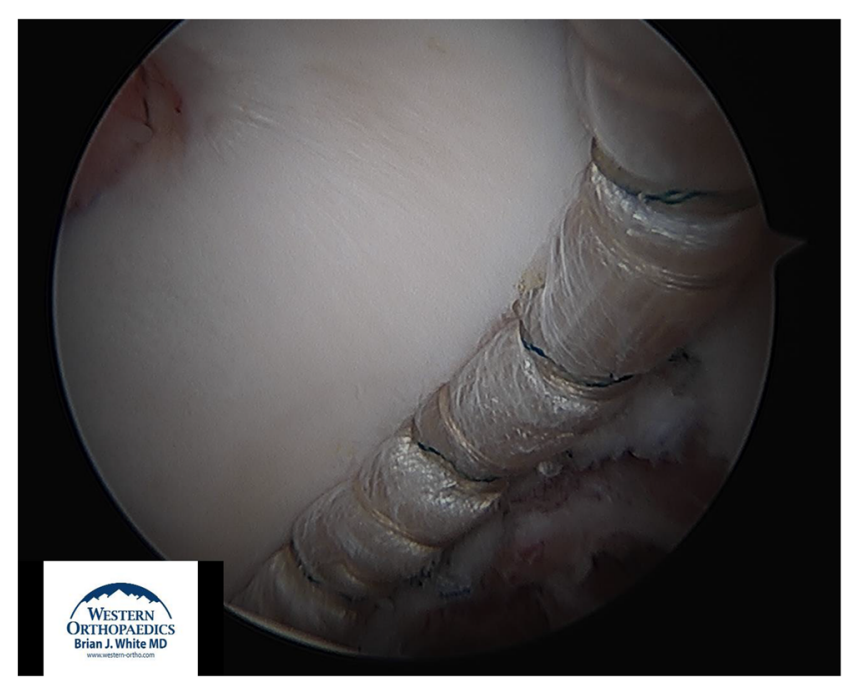

Fig. 5 View from the anteromedial portal of a left hip showing the posterior portion of the same $13-\mathrm{cm}$ labral reconstruction

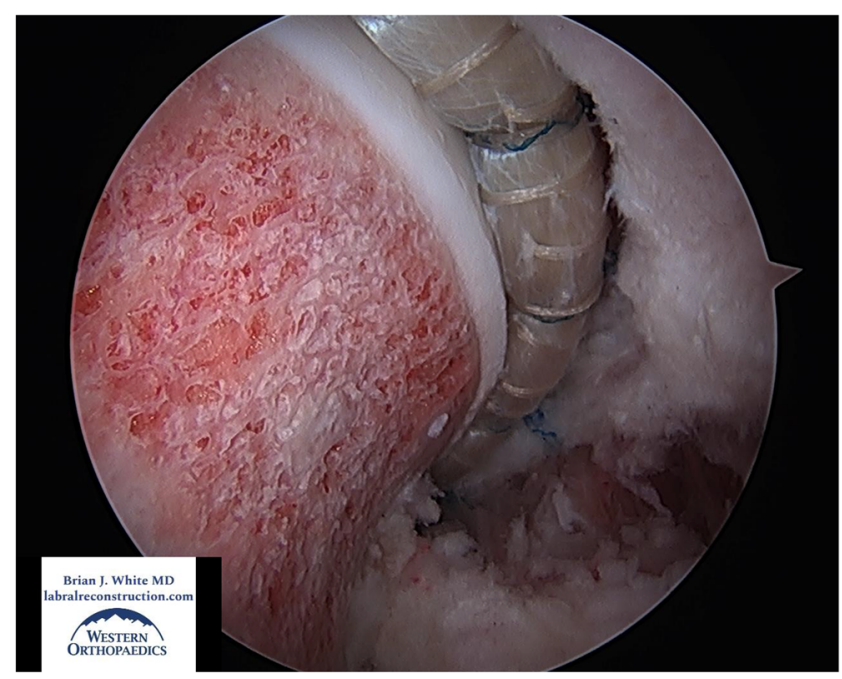

Fig. 6 View from the anteromedial portal of a left hip with the joint reduced and an anatomic seal formed between a $12.5-\mathrm{cm}$ allograft labral reconstruction and the femoral head

one versus two sutures, is determined by the baseline degree of capsular laxity.

\section{Outcomes}

Publications reporting on the outcomes of arthroscopic allograft labral reconstruction have continued to increase, with eight new studies having been published in 2020-2021, alone, on the topic $[4,10,12-14,16,19,46]$. Overall, evidence has shown highly positive patient-reported outcomes, low failure rates, and significant improvements in functional return to sports (Table 2). In the studies we reviewed, circumferential reconstruction was the predominantly utilized technique, and allograft preferences included iliotibial band, anterior tibialis, hamstring, and tensor fascia lata. Where conversion to total hip arthroplasty (THA) was a measurable outcome, only 142 of 1823 hips (7\%) were reported to have converted within the 1 to 2 years following surgery [4-6,12-14,19,20,24-26,46]. Among the hips that did not fail, authors reported improvements on a wide variety of validated patient-reported outcome (PRO) measures, range of motion, and radiographic correction of bony hip impingement morphology $[4,10,12-14,19,25,46]$. Where assessed, the mHHS showed an average improvement of 24 points [4-6,10,12-14,19,20,25,26,36]. Likewise, in a 2020 study on labral reconstruction in competitive athletes, Scanaliato [16] and colleagues found that all athletes reported substantial clinical benefit, with $87 \%$ of athletes returning to play in an average of 6.6 months. These findings were similar to Maldonado et al. [10] who found that $78 \%$ of athletes returned to sport following primary arthroscopic labral reconstruction. Overall, evidence points to both primary and revision hip arthroscopy with labral reconstruction to be a highly successful operation. 


\section{Revision: Reconstruction Versus Revision Repair}

Those who have failed a previous hip arthroscopy represent a challenging patient population and there has not been an evidence-based consensus on the best approach for them. As such, in 2016 we compared outcomes between patients who underwent revision hip arthroscopy with iliotibial band allograft labral reconstruction versus labral re-repair [5]. In our retrospective "repair or reconstruct" cohort study, we followed 113 hips ( $n=15$ re-repair, $n=98$ reconstruction) which had previously undergone previous labral repair or debridement ${ }^{5}$ for an average of 2.4 (reconstruction) to 4.7 (revision repair) years. Hips that underwent revision arthroscopy with labral revision-repair were 4.1 times $(n=7,50 \%$; 95\% CI 1.9-8.8; $p<.01)$ more likely to fail treatment when compared to patients who underwent revision arthroscopy with labral reconstruction $(n=11,13 \%)$ [5]. In addition to measuring failure rates, patients who underwent revision hip arthroscopy and labral reconstruction reported a more dramatic improvement in postoperative ratings on the Lower Extremity Functional Scale (LEFS) and mHHS, as well as improved pain as reported on the Visual Analogue Scale (VAS) [5]. For example, in patients who underwent revision arthroscopy with allograft labral reconstruction, the mean mHHS improved by 33 points, whereas the mean improvement in the revision repair group was 28 points [5]. In our revision-versus-repair study, we also sub-analyzed complete, circumferential labral grafts to shorter, segmental grafts and found a significantly lower failure rate with the longer grafts [5].

\section{Direct Comparison}

In regard to labral reconstruction and evaluation of clinical outcomes, it is of salient importance to mention that the lead author performed over 3,000 arthroscopic allograft labral reconstructions between July 2009 and February 2020 - both as primary and revision procedures [15]. In 2012, after performing both labral repairs and reconstructions for the two previous years, a concerning rate of failure was noted among patients who had undergone labral repair [15]. As a result, the lead author began exclusively performing labral reconstruction in all cases - a variable which represents a unique feature of his highly specialized practice and has subsequently allowed for investigation and comparison of outcomes in labral repair versus reconstruction on the same patient, where one hip underwent primary repair and the contralateral hip underwent primary reconstruction [26].

In 2018, we published a self-controlled cohort, or casecrossover, study investigating the differences in outcomes between primary labral repair and primary labral reconstruction in the same patient, performed on contralateral hips. We believe this study has provided some of the strongest evidence supporting primary arthroscopic labral reconstruction of the hip [26]. In our 2018 bilateral hip study, we evaluated a unique cohort of patients who had a labral repair on one hip and a labral reconstruction on the other. They were followed for over 2 years ( $M=56$ months), included 29 patients (58 hips), 23 females and six males, and were an average age of 32.6 years of age (range: 14.9 to 51.6 years) [26]. Their hips were radiographically similar and the only variable in the study was the labral treatment. At a minimum of 2-year follow-up and with $100 \%$ patient participation, none of the hips having undergone primary labral reconstruction had failed, whereas 9 labral repairs failed $(31 \%, p<.01)$ [26]. The patients whose labral repairs failed then elected to have a third surgery to convert their failed repair to a reconstruction.

In addition to differences in treatment failure rates, we found that patients who had undergone labral reconstruction noted superior outcomes compared to repair on a number of patientreported outcomes, such as the mHHS, LEFS, VAS, and with average pain with activities of daily living (ADLs) [26]. Additionally, patients who underwent labral reconstruction in our bilateral hip study demonstrated more notable improvement compared to what has been described as average patientreported improvements in other studies evaluating the outcomes of labral reconstructions $[5,6,26]$ as well as what has been described as average patient-reported improvements in other studies evaluating the outcomes of labral repair [48]. For example, we found that in patients who underwent primary labral reconstruction, there was an average 33-point improvement on the mHHS [26], as compared to an average 25-point improvement in other relevant studies [20,24,25,28-32,35,36].

\section{Graft Choice}

In a 2016 study [6], we evaluated the outcomes of a front-toback, circumferential allograft fixation technique for arthroscopic labral reconstruction. This was the first study to validate the use of allograft in labral reconstruction of the hip. In our "front-to-back" study, we found that of the 131 hips, which were followed for a minimum of 2 years, only 18 failed treatment and converted to THA or required revision arthroscopy. Of the remaining 113 hips, all demonstrated improvement in patient-reported outcomes, including an average 34point increase in postoperative mHHS $(p<.0001)$ and an average 27 -point increase in postoperative LEFS $(p<.0001)$.

\section{The Issue of Age}

In the area of hip arthroscopy, literature as it pertains to outcomes and age has focused on labral repair, not reconstruction. Two recent systematic reviews focused on hip arthroscopy outcomes in patients ages 40 years and older found that while there was an improvement in PROs the conversion to THA was as high as $30 \%{ }^{49,50}$. Likewise, another recent study found that hips with a Tönnis grade of more than 1 had as much as a $133 \%$ increased 
risk of converting to THA [51]. The role of age, as well as increased Tönnis grade, has called into question the appropriateness of arthroscopic hip surgery in an older population [4,49-53]. While we support the contraindication of arthroscopic hip surgery in patients with advanced hip arthritis, as it is not amenable to hip preservation, we believe age may be less of a determinant than is generally argued.

As such, in 2020 we published a study comparing outcomes of patients over the age of 40 who underwent primary labral reconstruction or primary labral repair. Our hypothesis contended that aged and chronically diseased labral tissue is compromised and does not heal well with labral repair. Improved results have been demonstrated when this labral tissue is removed, and the patient undergoes a circumferential labral reconstruction. In our "over-40" study, we followed 312 hips for approximately 4 years [4]. Cohorts were divided by age and procedure, including labral reconstruction in patients 40 years and older $(n=158)$, labral repair in patients 40 years and older $(n=93)$, and a control group of labral reconstruction in patients ages 30 to 39 years $(n=112)$ [4]. We found that failure was 3.29 times more likely in the over40 repair group when compared to the over-40 reconstruction group (relative rate, $3.29 ; p=.02$ ), and that there was no difference in failure rates between the 30 to 39 reconstruction group when compared to the over- 40 reconstruction group (relative rate, .58; $p=.37$ ) [4]. Labral repairs in the over-40 groups were found to have failed $22 \%$ of the time, whereas primary reconstructions failed only $8 \%$ of the time [4]. Likewise, patients in the over-40 reconstruction group demonstrated similar improvements on patient-reported outcomes, including the mHHS, LEFS, and VAS when compared to the 30 to 39 reconstruction group, both of which were superior to the over-40 repair group [4] $(p<.01)$. For example, patients in the over-40 reconstruction group reported a 37 -point improvement on the mHHS, whereas the over-40 repair group reported a 28 -point improvement.

\section{Conclusion}

Considering the positive evidence supporting labral reconstruction, the lead author performs only this procedure and is an advocate for labral reconstruction as both a primary and revision procedure as a more complete solution in the treatment of labral tears and FAI in the presence of irreparable labral tissue. It should also be regarded as the standard for revision hip arthroscopy. However, this stance is considered by some to be controversial as they still relegate labral reconstruction to a salvage operation. The decision to reconstruct the labrum should be made based out of respect for the operation and surgeon experience. When performed poorly, labral reconstruction has the potential to be catastrophic, especially in instances where the acetabular rim is overresected, thereby resulting in iatrogenic dysplasia. Conversely, when performed well, current evidence has demonstrated a high likelihood of success with labral reconstruction as a primary operation. In direct comparison studies to labral repair, the outcomes with labral reconstruction are similar or better depending on the institution.

The field of hip arthroscopy has grown exponentially in the last decade, and as a specialty, we have seen substantial advancement in the technical abilities of surgeons, and the evolution of the operation itself. Labral reconstruction plays a vital role in hip preservation by re-establishing normal anatomy and function especially in situations where the native labrum cannot be preserved. When compared to labral repair, research has shown that labral reconstruction has the potential to provide more significant improvements in pain and restoration of function. Labral reconstruction should have a role in the practice of every high-volume hip arthroscopist. Current evidence supports our recommendation that arthroscopic circumferential allograft labral reconstruction should be performed in all revision settings and in any instance when surgeons believe the labrum is irreparable. As evidenced by several recently published studies, patients across a broad spectrum of indications who undergo labral reconstruction, whether as a primary procedure or in the revision setting, demonstrate improved outcomes and low rates of failure. While a number of surgical techniques, including a variety of allograft options, have been described in the literature, our research and review of literature supports our recommendation for a circumferential, front-to-back fixation using an iliotibial band allograft, where the graft is measured and cut inside the joint $[6,15]$. The lead author welcomes all surgeons interested in learning this technique to come visit.

\section{Declarations}

Human and Animal Rights and Informed Consent This article does not contain any studies with human or animal subjects performed by any of the authors.

Conflict of interest Brian J. White reports that he is educational and product development consultant for Smith and Nephew, Allosource and Zimmer Biomet. He receives royalties from Zimmer Biomet. Shannon M. Constantinides declares no conflict of interest.

Open Access This article is licensed under a Creative Commons Attribution 4.0 International License, which permits use, sharing, adaptation, distribution and reproduction in any medium or format, as long as you give appropriate credit to the original author(s) and the source, provide a link to the Creative Commons licence, and indicate if changes were made. The images or other third party material in this article are included in the article's Creative Commons licence, unless indicated otherwise in a credit line to the material. If material is not included in the article's Creative Commons licence and your intended use is not permitted by statutory regulation or exceeds the permitted use, you will need to obtain permission directly from the copyright holder. To view a copy of this licence, visit http://creativecommons.org/licenses/by/4.0/. 


\section{References}

1. White BJ. At Issue: "Hip labral reconstruction: is the optimal method of hip labral reconstruction segmental or circumferential?". Orthopedics Today. Published online October. 2019.

2. Maradit Kremers H, Schilz SR, Van Houten HK, et al. Trends in utilization and outcomes of hip arthroscopy in the United States between 2005 and 2013. J Arthroplasty. 2017;32(3):750-5.

3. Bonazza NA, Homcha B, Liu G, Leslie DL, Dhawan A. Surgical trends in arthroscopic hip surgery using a large national database. Arthroscopy. 2018;34(6):1825-30.

4. White BJ, Patterson J, Scoles AM, Lilo AT, Herzog MM. Hip arthroscopy in patients aged 40 years and older: greater success with labral reconstruction compared with labral repair. Arthroscopy: The Journal of Arthroscopic \& Related Surgery. 2020;36(8):2137-44. https://doi.org/10.1016/j.arthro.2020.04.031.

5. White BJ, Patterson J, Herzog MM. Revision arthroscopic acetabular labral treatment: repair or reconstruct? Arthroscopy. 2016;32(12):2513-20.

6. White BJ, Herzog MM. Arthroscopic labral reconstruction of the hip using iliotibial band allograft and front-to-back fixation technique. Arthrosc Tech. 2016;5(1):e89-97.

7. Rahl MD, LaPorte C, Steinl GK, O'Connor M, Lynch TS, Menge TJ. Outcomes after arthroscopic hip labral reconstruction: a systematic review and meta-analysis. Am J Sports Med. 2020;48(7):174855 .

8. Trivedi NN, Sivasundaram L, Su CA, Knapik D, Nho SJ, Mather RC III, Salata MJ. Indications and outcomes of arthroscopic labral reconstruction of the hip: a systematic review. Arthroscopy. 2019;35(7):2175-86.

9. Maldonado DR, Kyin C, Chen SL, et al. In search of labral restoration function with hip arthroscopy: outcomes of hip labral reconstruction versus labral repair: a systematic review. Hip Int. Published online October 22. 2020:1120700020965162.

10. Maldonado DR, Chen SL, Yelton MJ, Rosinsky PJ, WalkerSantiago R, Shapira J, Lall AC, Domb BG. Return to sport and athletic function in an active population after primary arthroscopic labral reconstruction of the hip. Orthop J Sports Med. 2020;8(2): 2325967119900767.

11. Safran N, Rath E, Haviv B, Atzmon R, Amar E. The efficacy of labral reconstruction: a systematic review. Orthop J Sports Med. 2021;9(2):2325967120977088.

12. Domb BG, Kyin C, Go CC, et al. Arthroscopic circumferential acetabular labral reconstruction for irreparable Labra in the revision setting: patient-reported outcome scores and rate of achieving the minimal clinically important difference at a minimum 2-year follow-up. Am J Sports Med. Published online April 16. 2021: 3635465211005742.

13. Domb BG, Kyin C, Rosinsky PJ, Shapira J, Yelton MJ, Meghpara MB, Lall AC, Maldonado DR. Circumferential labral reconstruction for irreparable labral tears in the primary setting: minimum 2year outcomes with a nested matched-pair labral repair control group. Arthroscopy. 2020;36(10):2583-97.

14. Maldonado DR, Kyin C, Shapira J, et al. No difference in minimum two-year patient-reported outcome scores between circumferential and segmental labral reconstruction for the management of irreparable labral tear and femoroacetabular impingement syndrome in the primary setting. A Propensity-Matched Study. Arthroscopy. Published online April 30. 2021. https://doi.org/10.1016/j.arthro. 2021.04.037.

15. White BJ, Herzog MM. Arthroscopic labral reconstruction of the hip: a decade of growing evidence and technical evolution. Techniques in Orthopaedics. 2021;Publish Ahead of Print. https:// doi.org/10.1097/BTO.0000000000000487.
16. Scanaliato JP, Chasteen J, Polmear MM, Salfiti C, Wolff AB. Primary and revision circumferential labral reconstruction for femoroacetabular impingement in athletes: return to sport and technique. Arthroscopy. 2020;36(10):2598-610.

17. Al Mana L, Coughlin RP, Desai V, Simunovic N, Duong A, Ayeni OR. The hip labrum reconstruction: indications and outcomes-an updated systematic review. Curr Rev Musculoskelet Med. 2019;12(2):156-65.

18. Bessa FS, Williams BT, Polce EM, Neto M, Garcia FL, Leporace G, Metsavaht L, Chahla J. Indications and outcomes for arthroscopic hip labral reconstruction with autografts: a systematic review. Front Surg. 2020;7:61.

19. Bodendorfer BM, Alter TD, Carreira DS, et al. Multicenter outcomes after primary hip arthroscopy: a comparative analysis of two-year outcomes after labral repair, segmental labral reconstruction or circumferential labral reconstruction. Arthroscopy: The Journal of Arthroscopic \& Related Surgery. Published online. 2021. https://doi.org/10.1016/j.arthro.2021.05.013.

20. Carreira DS, Kruchten MC, Emmons BR, Martin RL. Arthroscopic labral reconstruction using fascia lata allograft: shuttle technique and minimum two-year results. J Hip Preserv Surg. 2018;5(3): 247-58.

21. Chandrasekaran S, Darwish N, Close MR, Lodhia P, Suarez-Ahedo C, Domb BG. Arthroscopic reconstruction of segmental defects of the hip labrum: results in 22 patients with mean 2-year follow-up. Arthroscopy. 2017;33(9):1685-93.

22. Domb BG, Battaglia MR, Perets I, Lall AC, Chen AW, OrtizDeclet V, Maldonado DR. Minimum 5-year outcomes of arthroscopic hip labral reconstruction with nested matched-pair benchmarking against a labral repair control group. Am J Sports Med. 2019;47(9):2045-55.

23. Maldonado DR, Lall AC, Walker-Santiago R, Rosinsky P, Shapira J, Chen JW, Domb BG. Hip labral reconstruction: consensus study on indications, graft type and technique among high-volume surgeons. J Hip Preserv Surg. 2019;6(1):41-9.

24. Rathi R, Mazek J. Arthroscopic acetabular labral reconstruction with fascia lata allograft: clinical outcomes at minimum one-year follow-up. Open Orthop J. 2017;11:554-61.

25. Scanaliato JP, Christensen DL, Salfiti C, Herzog MM, Wolff AB. Primary circumferential acetabular labral reconstruction: achieving outcomes similar to primary labral repair despite more challenging patient characteristics. Am J Sports Med. 2018;46(9):2079-88.

26. White BJ, Patterson J, Herzog MM. Bilateral hip arthroscopy: direct comparison of primary acetabular labral repair and primary acetabular labral reconstruction. Arthroscopy. 2018;34(2):433-40.

27. White BJ, Stapleford AB, Hawkes TK, Finger MJ, Herzog MM. Allograft use in arthroscopic labral reconstruction of the hip with front-to-back fixation technique: minimum 2-year follow-up. Arthroscopy. 2016;32(1):26-32.

28. Amar E, Sampson TG, Sharfman ZT, Caplan A, Rippel N, Atzmon R, Drexler M, Rath E. Acetabular labral reconstruction using the indirect head of the rectus femoris tendon significantly improves patient reported outcomes. Knee Surg Sports Traumatol Arthrosc. 2018;26(8):2512-8.

29. Boykin RE, Patterson D, Briggs KK, Dee A, Philippon MJ. Results of arthroscopic labral reconstruction of the hip in elite athletes. Am J Sports Med. 2013;41(10):2296-301.

30. Domb BG, El Bitar YF, Stake CE, Trenga AP, Jackson TJ, Lindner D. Arthroscopic labral reconstruction is superior to segmental resection for irreparable labral tears in the hip: a matched-pair controlled study with minimum 2-year follow-up. Am J Sports Med. 2014;42(1):122-30.

31. Geyer MR, Philippon MJ, Fagrelius TS, Briggs KK. Acetabular labral reconstruction with an iliotibial band autograft: outcome and survivorship analysis at minimum 3-year follow-up. Am J Sports Med. 2013;41(8):1750-6. 
32. Lebus GF, Briggs KK, Dornan GJ, McNamara S, Philippon MJ. Acetabular labral reconstruction: development of a tool to predict outcomes. Am J Sports Med. 2018;46(13):3119-26.

33. Matsuda DK, Burchette RJ. Arthroscopic hip labral reconstruction with a gracilis autograft versus labral refixation: 2-year minimum outcomes. Am J Sports Med. 2013;41(5):980-7.

34. Philippon MJ, Arner JW, Crawford MD, Bolia IK, Briggs KK. Acetabular labral reconstruction with iliotibial band autograft: outcome and survivorship at a minimum 10-year follow-up. $J$ Bone Joint Surg Am. 2020;102(18):1581-7.

35. Philippon MJ, Briggs KK, Hay CJ, Kuppersmith DA, Dewing CB, Huang MJ. Arthroscopic labral reconstruction in the hip using iliotibial band autograft: technique and early outcomes. Arthroscopy. 2010;26(6):750-6.

36. Rathi R, Mazek J. Arthroscopic acetabular labral reconstruction with rectus femoris tendon autograft: our experiences and early results. J Orthop. 2018;15(3):783-6.

37. Philippon MJ, Nepple JJ, Campbell KJ, Dornan GJ, Jansson KS, LaPrade RF, Wijdicks CA. The hip fluid seal—Part I: the effect of an acetabular labral tear, repair, resection, and reconstruction on hip fluid pressurization. Knee Surg Sports Traumatol Arthrosc. 2014;22(4):722-9.

38. Nepple JJ, Philippon MJ, Campbell KJ, Dornan GJ, Jansson KS, LaPrade RF, Wijdicks CA. The hip fluid seal-Part II: The effect of an acetabular labral tear, repair, resection, and reconstruction on hip stability to distraction. Knee Surg Sports Traumatol Arthrosc. 2014;22(4):730-6.

39. Lee S, Wuerz TH, Shewman E, McCormick FM, Salata MJ, Philippon MJ, Nho SJ. Labral reconstruction with iliotibial band autografts and semitendinosus allografts improves hip joint contact area and contact pressure: an in vitro analysis. Am J Sports Med. 2015;43(1):98-104.

40. Storaci HW, Utsunomiya H, Kemler BR, Rosenberg SI, Dornan GJ, Brady AW, Philippon MJ. The hip suction seal, Part I: The role of acetabular labral height on hip distractive stability. Am J Sports Med. 2020;48(11):2726-32.

41. Utsunomiya H, Storaci HW, Rosenberg SI, Kemler BR, Dornan GJ, Brady AW, Philippon MJ. The hip suction seal, Part II: The effect of rim trimming, chondrolabral junction separation, and labral repair/refixation on hip distractive stability. The American Journal of Sports Medicine. 2020;48(11):2733-9. https://doi.org/ $10.1177 / 0363546520941859$.

42. Mayo BC, Rosinsky PJ, Kyin C, et al. Characterizing irreparable: a retrospective machine learning analysis of patients who undergo primary labral reconstruction during hip arthroscopy. J Hip Preserv Surg. Published online February 12. 2021:660-9. https:// doi.org/10.1093/jhps/hnab005.
43. Lodhia P, McConkey MO, Leith JM, Maldonado DR, Brick MJ, Domb BG. Graft options in hip labral reconstruction. Curr Rev Musculoskelet Med. 2021;14(1):16-26.

44. Atzmon R, Radparvar JR, Sharfman ZT, Dallich AA, Amar E, Rath E. Graft choices for acetabular labral reconstruction. J Hip Preserv Surg. 2018;5(4):329-38.

45. Moya E, Natera LG, Cardenas C, Astarita E, Bellotti V, Ribas M. Reconstruction of massive posterior nonrepairable acetabular labral tears with peroneus brevis tendon allograft: arthroscopy-assisted mini-open approach. Arthrosc Tech. 2016;5(5):e1015-22.

46. Chen MJ, Hollyer I, Pun SY, Bellino MJ. Acetabular labral reconstruction with medial meniscal allograft: preliminary results of a new surgical technique. Eur J Orthop Surg Traumatol. Published online May 24. 2021. https://doi.org/10.1007/s00590-021-02986-2.

47. Maldonado DR, Lall AC, Laseter JR, Kyin C, Chen JW, Go CC, Domb BG. Primary hip arthroscopic surgery with labral reconstruction: is there a difference between an autograft and allograft? Orthop J Sports Med. 2019;7(3):2325967119833715.

48. Riff AJ, Kunze KN, Movassaghi K, et al. Systematic review of hip arthroscopy for femoroacetabular impingement: the importance of labral repair and capsular closure. Arthroscopy. 2019;35(2):646656.e3.

49. Horner NS, Ekhtiari S, Simunovic N, Safran MR, Philippon MJ, Ayeni OR. Hip arthroscopy in patients age 40 or older: a systematic review. Arthroscopy. 2017;33(2):464-475.e3.

50. Griffin DW, Kinnard MJ, Formby PM, McCabe MP, Anderson TD. Outcomes of hip arthroscopy in the older adult: a systematic review of the literature. Am J Sports Med. 2017;45(8):1928-36.

51. Zimmerer A, Ramoser A, Streit M, et al. Osteoarthrosis, advanced age, and female sex are risk factors for inferior outcomes after hip arthroscopy and labral debridement for femoroacetabular impingement syndrome: case series with minimum 10-year follow-up. Arthroscopy. 2021; https://www.sciencedirect.com/science/article/ pii/S0749806321000384.

52. Hartigan DE, Wojnowski N, Krych AJ, Levy BA, Domb BG. Arthroscopic treatment of labral tears in patients 65 years and older. Orthopedics. 2020;43(6):e579-84.

53. Honda E, Utsunomiya H, Hatakeyama A, Nakashima H, Suzuki H, Matsuda DK, Sakai A, Uchida S. Patients aged in their 70s do not have a high risk of progressive osteoarthritis following arthroscopic femoroacetabular impingement correction and labral preservation surgery. Knee Surgery, Sports Traumatology, Arthroscopy. 2020;28(5):1648-55. https://doi.org/10.1007/s00167-019-05520-4.

Publisher's note Springer Nature remains neutral with regard to jurisdictional claims in published maps and institutional affiliations. 